\title{
Influence of Earthquake on Deformation and Stability of a Certain Landslide
}

\author{
Yinger Deng ${ }^{1, \text { a }}$, Zhimin Zhao, b and Xin Peng ${ }^{1, c}$ \\ ${ }^{1}$ State Key Laboratory of Geohazard Prevention and Geoenvironment Protection, Chengdu \\ University of Technology, Chengdu 610059, China \\ a546730457@qq.com, bzhaozhimin@cdut.cn, ${ }^{c} 2250656391 @ q q . c o m$
}

\begin{abstract}
Keywords: deformation, stability of landslide, weak permeable media, earthquake intensity, pore water pressure
\end{abstract}

Abstract. This paper focused on change characteristics of deformation and stability of certain a landslide under conditions of earthquake. The mathematical model of dynamic analysis of earthquake was utilized for deformation and stability of the landslide with weak permeable media. This paper studied change characteristics of deformation and stability of the landslide with changes of conditions of earthquake intensity. Results show that: (1) the landslide displacement and maximum shear strain increase with earthquake intensity; (2) the excess pore water pressure resulted from earthquake rises fast in a short time and decrease with elevation; and (3) the stability decreases and number less than the critical value increase with earthquake intensity. Prevention measures should be adopted for the landslide. The results can provide stability evaluation and engineering treatment of the landslide with scientific basis.

\section{Introduction}

Influence of earthquake on a landslide involves geological engineering and geotechnical engineering. Research on the Influence has important theoretical and practical significance. Some scholars have considered earthquake effect on a landslide such as Celebi [1], Hartzell [2], Papadopoulos [3] and Chigira et al. [4]. Zhou et al. [5] researched some characteristics of earthquake-induced landslide in southwestern china. Earthquake takes place frequently in the southwest of China. It is one of the important reasons why geohazard occurs repeatedly in the southwest of China [5]. Sun et al. [6] presented developing and distributing characteristics of collapses and landslides during strong historic earthquake in China. Liu et al. [7] reviewed advance on topographic amplification effects of seismic response.

In this paper, we take certain a landslide as a research object and focused on deformation and stability of the landslide. We will carry out dynamic analysis of earthquake in the landslide with weak permeable media by a mathematical model. Moreover, we will calculate change characteristics of deformation and stability of the landslide with earthquake intensity. All the researches will provide evaluation of engineering safety of the field with scientific basis.

\section{Area Range and Basic Characteristics of Certain a Landslide}

Certain a landslide with weak permeable media was selected. Range of the research area is shown in Fig. 1. The landslide is composed of Quaternary loose sediment accumulation, belongs to large soil landslide of large accumulation. And it is porous media with weak permeable media. Landforms characteristic of the landslide belongs to a typical erosion structure. Landslide front is located at the edge of the slope. The trailing edge of the landslide is hollow. The relative elevation difference between of the front and the trailing edge of the landslide is about $265 \mathrm{~m}$. The north side and the south side are bounded by gullies. The slope angle of the interface between the bedrock and overburden is large and provides the terrain conditions for the landslide. Sliding bed is bedrock. The slide surface shape is a broken line. Slip zone is yellow plastic clay. The landslide has tension cracks because of deformation. Seismic activity is frequent and provides dynamic conditions for the landslide. 


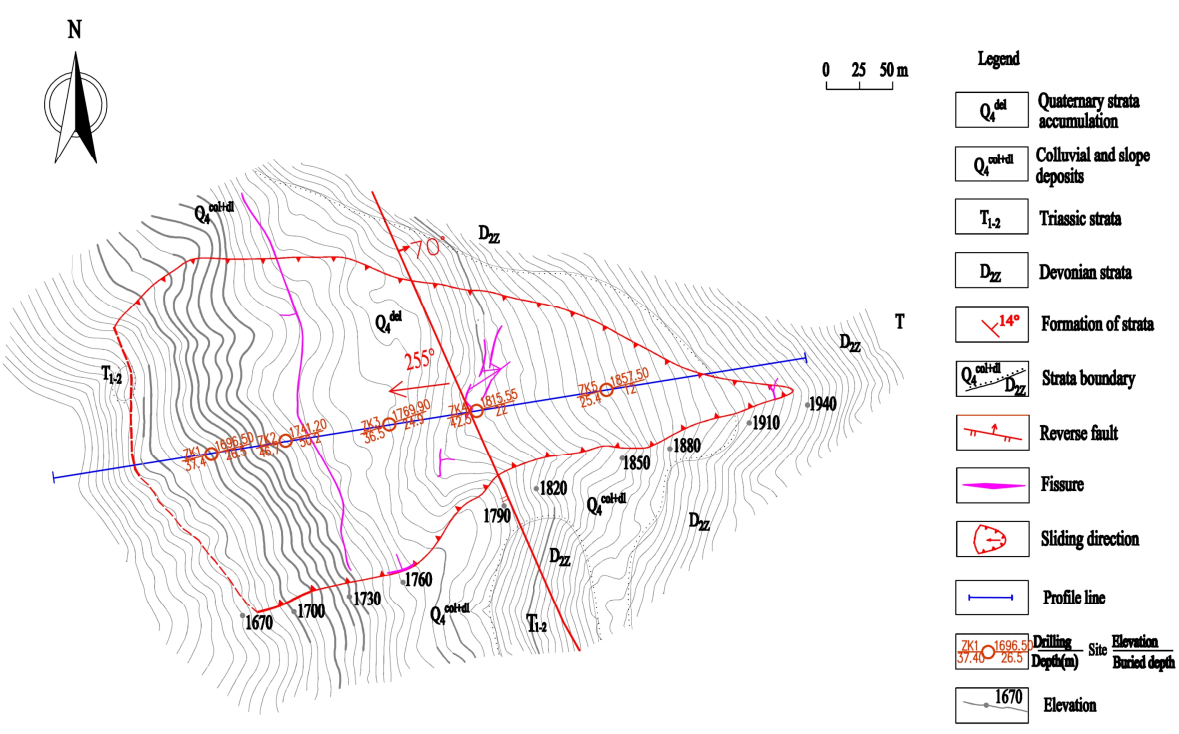

Fig. 1 Research area range (N: North)

\section{Mathematical Model of Dynamic Analysis of Earthquake}

An equation of motion under consition of dynamic earthquake is given by equation (1).

$$
[M]\{\ddot{a}\}+[D]\{a\}+[K]\{a\}=[F]
$$

where, $[M]$ is mass matrix, $[D]$ is damping matrix, $[K]$ is stiffness matrix, $[F]$ is load vector, $\{\ddot{a}\}$ is acceleration, $\{a\}$ is velocity, $\{a\}$ is displacement. $[F]$ can be written as

$$
\{F\}=\left\{F_{b}\right\}+\left\{F_{s}\right\}+\left\{F_{n}\right\}+\left\{F_{g}\right\}
$$

where, $\left\{F_{b}\right\}$ is volume force, $\left\{F_{s}\right\}$ is pressure, $\left\{F_{n}\right\}$ is concentrated force, $\left\{F_{g}\right\}$ is earthquake force. Concentrated mass matrix is

$$
[M]=\int_{v} \rho[\psi] d v
$$

Consistent mass matrix is

$$
[M]=\int_{v} \rho\langle N\rangle^{T}\langle N\rangle d v
$$

where, $\rho$ is mass density, $\langle N\rangle$ is row vector of difference function, $[\psi]$ is diagonal matrix od mass distribution factor. Damping matrix can be written as

$$
[D]=\alpha[M]+\beta\{K\}
$$

where, $\alpha$ and $\beta$ are coefficient. Damping ratio is

$$
\eta=\frac{\alpha+\beta \omega^{2}}{2 \omega}
$$

where, $\omega$ is vibration frequency. Stiffness matrix is 


$$
[K]=\int_{v}[B]^{T}[C][B] d v
$$

where, $[B]$ is stress strain matrix, $[C]$ is natural characteristic matrix. Shear strain is

$$
\{\varepsilon\}=\left\{\begin{array}{l}
\varepsilon_{x} \\
\varepsilon_{y} \\
\varepsilon_{z} \\
\gamma_{x y}
\end{array}\right\}
$$

Relationship between shear strain vector and displacement is

$$
\{\varepsilon\}=[B]\left\{\begin{array}{l}
u \\
v
\end{array}\right\}
$$

where, $[B]$ is stress matrix, $u, v$ are nodal displacement in the direction of $\mathrm{x}$ and $\mathrm{y} .[B]$ is

$$
[B]=\left[\begin{array}{cccc}
\frac{\partial N_{1}}{\partial x} & 0 & \frac{\partial N_{3}}{\partial x} & 0 \\
0 & \frac{\partial N_{1}}{\partial y} & 0 & \frac{\partial N_{3}}{\partial y} \\
0 & 0 & 0 & 0 \\
\frac{\partial N_{1}}{\partial x} & \frac{\partial N_{1}}{\partial y} & \frac{\partial N_{3}}{\partial x} & \frac{\partial N_{3}}{\partial y}
\end{array}\right]
$$

Linear elastic constitutive equation is

$$
\begin{aligned}
& {[\sigma]=[C]\{\varepsilon\}} \\
& {[C]=\frac{E}{(1+v)(1-2 v)}\left[\begin{array}{cccc}
1-v & v & v & 0 \\
v & 1-v & v & 0 \\
v & v & 1-v & 0 \\
0 & 0 & 0 & \frac{1-2 v}{2}
\end{array}\right]}
\end{aligned}
$$

where, $E$ is Young's modulus, $v$ is Poisson's ratio. Linear elastic model is

$$
\left\{\begin{array}{l}
\sigma_{x} \\
\sigma_{y} \\
\sigma_{z} \\
\tau_{x y}
\end{array}\right\}=\frac{E}{(1+v)(1-2 v)}\left[\begin{array}{cccc}
1-v & v & v & 0 \\
v & 1-v & v & 0 \\
v & v & 1-v & 0 \\
0 & 0 & 0 & \frac{1-2 v}{2}
\end{array}\right]\left\{\begin{array}{l}
\varepsilon_{x} \\
\varepsilon_{y} \\
\varepsilon_{z} \\
\gamma_{x y}
\end{array}\right\}
$$

where, $\varepsilon_{z}$ is 0 for plane strain.

\section{Basic Parameters}

Basic parameters of rock and soil mechanics are shown in the table 1. Horizontal peak accelerations of earthquake are shown in the table 2.

\section{Results and Discussion}

The deformation and stability of the landslide under conditions of earthquake have some characteristics. The maximum shear strain of the landslide increases gradually with earthquake intensity. The maximum 
shear strain of the initial state is located at the foot of the landslide. The maximum shear strain is in the upper part of the landslide under the condition of earthquake. The excess pore water pressure resulted from earthquake rises fast in a short time and decrease with elevation. The permanent displacement of the landslide increases and stability of the landslide coefficient decreases gradually with earthquake intensity. The number less than the critical value increase with earthquake intensity. Cumulative permanent displacement and minimum stability coefficient is shown in table 3.

Table 1 Basic mechanics parameters

\begin{tabular}{cccccc}
\hline Media & $\begin{array}{c}\text { Density } \\
\left(\mathrm{g} / \mathrm{cm}^{3}\right)\end{array}$ & $\begin{array}{c}\text { Elastic modulus } \\
(\mathrm{Pa})\end{array}$ & $\begin{array}{c}\text { Shear modulus } \\
(\mathrm{Pa})\end{array}$ & $\begin{array}{c}\text { Damping } \\
\text { ratio }\end{array}$ & $\begin{array}{c}\text { Poisson's } \\
\text { ratio }\end{array}$ \\
\hline Gravel soils & 2.0 & $2.0 \times 10^{7}$ & $8.3 \times 10^{6}$ & 0.15 & 0.2 \\
Schist- Slate & 2.5 & $2.0 \times 10^{10}$ & $8.0 \times 10^{9}$ & 0.15 & 0.15 \\
Marble & 2.7 & $3.0 \times 10^{10}$ & $1.25 \times 10^{10}$ & 0.15 & 0.15 \\
\hline
\end{tabular}

Table 2 Horizontal peak accelerations of earthquake

\begin{tabular}{ccc}
\hline Serial number & Earthquake intensity & Horizontal peak acceleration $\left(\mathrm{m} / \mathrm{s}^{2}\right)$ \\
\hline 1 & 7 & 0.15 \\
2 & 8 & 0.2 \\
3 & 9 & 0.4 \\
\hline
\end{tabular}

Table 3 Cumulative permanent displacement and minimum stability coefficient

\begin{tabular}{ccccc}
\hline $\begin{array}{c}\text { Earthquake } \\
\text { intensity }\end{array}$ & $\begin{array}{c}\text { minimum stability } \\
\text { coefficient }\end{array}$ & $\begin{array}{c}\text { Number less than } \\
\text { critical value }\end{array}$ & $\begin{array}{c}\text { Cumulative permanent } \\
\text { displacement }(\mathrm{mm})\end{array}$ & Stability \\
\hline 7 & 1.15 & 0 & 288.2 & stable \\
8 & 1.08 & 4 & 384.2 & metastable \\
9 & 0.92 & 7 & 768.4 & unstable \\
\hline
\end{tabular}

\section{Conclusions}

The landslide displacement and maximum shear strain increase with earthquake intensity. The excess pore water pressure resulted from earthquake rises fast in a short time and decrease with elevation. The stability decreases and number less than the critical value increase with earthquake intensity.

\section{Acknowledgements}

This work was supported by the National Natural Science Foundation of China (41172277). The authors would like to thank Professors X. M. Fu, X. J. Yu and Dr. Y. H. Yang for their help.

\section{References}

[1] M. Celebi: Bulletin of the Seismological Society of America Vol.77 (1987), p.1141.

[2] S.H. Hartzell, D.L. Carver, K.W. King: Bulletin of the Seismological Society of America Vol.84 (1994), p.1336.

[3] G. A. Papadopoulos, A. Plessa: EngineeringGeology Vol.58(2000), p.377.

[4] Y. Chigira: Engineering Geology Vol.82 (2006), p.202.

[5] B.G. Zhou, Y.M. Wang: Northwestern Seismological Journal Vol.16 (1994), p.95 (In Chinese).

[6] C.S. Sun, H.W. Cai: Journal of Natural Disasters Vol.6 (1997), p.25 (In Chinese).

[7] H. B. Liu, X. Zhu: World information on earthquake engineering Vol.15 (1999), 20 (In Chinese). 